\section{Re: The 2019 core-needle biopsy practice guidelines}

\author{
Ji-hoon Kim
}

Department of Radiology, Seoul National University College of Medicine, Seoul, Korea

We sincerely appreciate your interest in our paper, entitled "Distribution and malignancy risk of six categories of the pathology reporting system for thyroid core-needle biopsy in 1,216 consecutive thyroid nodules" [1].

Apart from the various benefits of core-needle biopsy (CNB) for the diagnosis of thyroid nodules, we believe that our paper has clinical significance in the diverse presentation of six categories of the pathology reporting system for thyroid CNB according to pathologic criteria [2-6].

We would like to respond to your thoughtful comments as follows. First, it was unfortunate that our pathologic analysis was not based on the 2019 clinical practice guidelines for CNB, but those guidelines were not published until after we prepared our paper [7]. We agree that the nondiagnostic criteria of the 2019 clinical practice guidelines are more reasonable, and our nondiagnostic rate of $1.8 \%$ might have been higher if the new criteria were applied. Second, we agree with your comment that the relatively high malignancy rate $(23.1 \%)$ in the nondiagnostic category of our data might have been related to the assumption that many nondiagnostic cases might be lost to follow-up or categorized as "other" because the pathologic criteria in our paper did not follow the new CNB guidelines [8]. Nonetheless, we still think that even CNB has the potential to miss malignancies because a small malignant portion of thyroid nodules categorized as nondiagnostic using CNB could miss being targeted in the CNB procedure. Finally, we wholeheartedly agree with your comment that we need to reduce the unnecessary biopsy rate in our daily practice, and we believe that CNB will reduce the unnecessary biopsy rate compared with fine-needle aspiration by decreasing the need for repeated biopsies, as stated in our paper.

ORCID: Ji-hoon Kim: https://orcid.org/0000-0002-6349-6950

\section{Conflict of Interest}

No potential conflict of interest relevant to this article was reported.

\section{References}

1. Son HM, Kim JH, Kim SC, Yoo RE, Bae JM, Seo H, et al. Distribution and malignancy risk of six categories of the pathology reporting system for thyroid core-needle biopsy in 1,216 consecutive thyroid nodules. Ultrasonography 2020;39:159-165.

2. Na DG, Kim JH, Sung JY, Baek JH, Jung KC, Lee $H$, et al. Core-needle biopsy is more useful than repeat fine-needle aspiration in thyroid nodules read as nondiagnostic or atypia of undetermined significance by the Bethesda system for reporting thyroid cytopathology. Thyroid 2012;22:468-475.

3. Yi KS, Kim JH, Na DG, Seo H, Min HS, Won JK, et al. Usefulness of core needle biopsy for thyroid nodules with macrocalcifications: comparison with fine-needle aspiration. Thyroid 2015;25:657-664.

4. Trimboli P, Giovanella L. Reliability of core needle biopsy as a second-line procedure in thyroid nodules

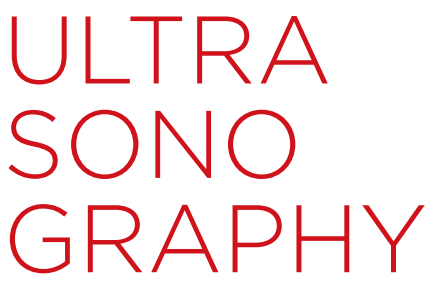

\section{LETTER}

https://doi.org/10.14366/usg.20060 pISSN: 2288-5919 - elSSN: 2288-5943 Ultrasonography 2020;39:313-314

Received: April 27, 2020

Revised: April 27, 2020

Accepted: April 29, 2020

Correspondence to: Ji-hoon Kim, MD, Department of Radiology, Seoul National University College of Medicine, 101 Daehak-ro, Jongno-gu, Seoul 03080, Korea

Tel. $+82-2-2072-3617$

Fax. $+82-2-747-7418$

E-mail: jihnkim@snu.ac.kr
This is an Open Access article distributed under the terms of the Creative Commons Attribution NonCommercial License (http://creativecommons.org/ licenses/by-nc/4.0/) which permits unrestricted noncommercial use, distribution, and reproduction in any medium, provided the original work is properly cited.

Copyright (C 2020 Korean Society of Ultrasound in Medicine (KSUM)

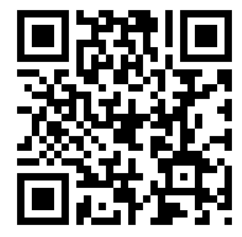

How to cite this article:

Kim JH. Re: The 2019 core-needle biopsy practice guidelines. Ultrasonography. 2020 Jul;39(3):313-314. 
with an indeterminate fine-needle aspiration report: a systematic review and meta-analysis. Ultrasonography 2018;37:121-128.

5. Hong MJ, Na DG, Kim SJ, Kim DS. Role of core needle biopsy as a first-line diagnostic tool for thyroid nodules: a retrospective cohort study. Ultrasonography 2018;37:244-253.

6. Chung SR, Baek JH, Choi YJ, Sung TY, Song DE, Kim TY, et al. The role of core needle biopsy for the evaluation of thyroid nodules with suspicious ultrasound features. Korean J Radiol 2019;20:158165.
7. Jung CK, Baek JH, Na DG, Oh YL, Yi KH, Kang HC. 2019 Practice guidelines for thyroid core needle biopsy: a report of the Clinical Practice Guidelines Development Committee of the Korean Thyroid Association. J Pathol Transl Med 2020;54:64-86.

8. Jung CK, Min HS, Park HJ, Song DE, Kim JH, Park SY, et al. Pathology reporting of thyroid core needle biopsy: a proposal of the Korean Endocrine Pathology Thyroid Core Needle Biopsy Study Group. J Pathol Transl Med 2015;49:288-299. 